ISSN: 2792-3967

DO1: https://doi.org//0.5370I/shj.v2il.35

\title{
EL USO DE LA PRERROGATIVA REGIA EN LA MONARQUÍA ESPAÑOLA E ITALIANA DEL ÚLTIMO TERCIO DEL SIGLO XIX: ¿UN GOBIERNO PARLAMENTARIO?'1
}

THE USE OF THE ROYAL PREROGATIVE IN THE SPANISH AND ITALIAN MONARCHY OF THE LAST THIRD OF THE 19TH CENTURY: A PARLIAMENTARY GOVERNMENT?

\author{
Aitor Alaña Pérez \\ Universidad Complutense de Madrid \\ ORCID: 0000-0003-2608-6220 \\ aalana@ucm.es

\section{| Resumen}

A lo largo del 0chocientos, la mayoría de los estados europeos se fueron constituyendo, en un sentido amplio, en monarquías de corte liberal, al dotarse de un texto constitucional que buscó, entre otras cuestiones, delimitar las funciones que debía desempeñar el Trono ante una nueva realidad política solo antes vista en Inglaterra. Del mismo modo, se suele observar a finales del siglo XIX la cristalización de una forma de gobierno parlamentario en buena parte de estas monarquías liberales, adaptando, la mayoría, el modelo inglés que se había implementado satisfactoriamente en este país desde el siglo XVII. Este acercamiento al ideal británico de gobierno monárquico fue el camino emprendido por España e Italia a lo largo de la centuria, puesto que ambos países diseñaron un marco jurídico y una forma de gobierno que evolucionó, con los años, a una forma de gobierno con tintes parlamentarios. Sin embargo, los monarcas españoles e italianos siguieron disponiendo de un elevado número de prerrogativas que sus respectivos textos jurídicos les atribuyeron, herencias del pasado y, sobre todo, una praxis política que hizo que los usos y convenciones constitucionales asumidas por el poder monárquico manifestasen la fragilidad del parlamentarismo en estos dos países mediterráneos. El presente trabajo pretende abordar el uso de la prerrogativa regia durante la Restauración española y la Italia del Risorgimento para analizar, en perspectiva comparada, hasta qué punto la cultura política de ambos países puede ser considerada, a la altura de 1900, una cultura política de gobierno parlamentario.

Palabras clave: Parlamentarismo; Monarquía; Constitución; España; Italia; Historia contemporánea de Europa.

\section{Abstract}

Abstract: In the 19th century, the majority of european states were constituted, in a broad sense, in liberal monarchies, by endowing

I Recibido/Received: |5/|0/202|

Aceptado/Accepted: $21 / 01 / 2022$

El presente trabajo se inserta dentro del proyecto de investigación "Cultura del honor, política y esfera pública en la España liberal (I8331890)" financiado por el Ministerio de Ciencia, Innovación y Universidades (Ref. ${ }^{a}$ PGC2018-093698-B-I00) y del programa de Formación del Profesorado Universitario, financiado por el Ministerio de Universidades (Ref ${ }^{a}$ FPU19/03573).

SHJ, 2022, 2(I), pp. I-24. ISSN: 2792-3967 
themselves with a constitutional text that sought, among other issues, delimiting the functions to be performed by the Throne in the face of a new political reality only seen before in England. Similarly, the crystallization of a form of parliamentary government in much of these liberal monarchies is usually observed at the end of the 19th century adapting, most of them, the English model that had been successfully implemented in this country since the 17th century. This approach to the British ideal of monarchical government was the path taken by Spain and Italy throughout the century, since both countries designed a legal framework and a form of government that evolved, over the years, to a form of government with parliamentary overtones. However, the Spanish and Italian monarchs continued to have a large number of prerogatives attributed to them by their respective legal texts, legacies of the past and above all, a political praxis that made the constitutional customs and conventions assumed by the monarchical power manifest the fragility of parliamentarism in these two Mediterranean countries. This paper aims to address the use of the royal prerogative during the Spanish Restoration and the Italy of the Risorgimento to analyze, in comparative perspective, to what extent the political culture of both countries can be considered, at the height of 1900 , a political culture of parliamentary government.

Keywords: Parliamentarism; Monarchy; Constitution; Spain; Italy; European Modern History.

\section{| Introducción |}

Las monarquías europeas vivieron a lo largo del siglo XIX una progresiva adaptación a las nuevas realidades políticas y sociales que trajeron consigo las denominadas "revoluciones liberales". Con el objetivo de analizar el nuevo encaje de la Corona en el complejo proceso político de la monarquía liberal del siglo XIX, Ignacio Marcuello (2020), en su reciente obra Rey, Cortes y Formas de Gobierno en la Monarquía Liberal española del siglo XIX. Criterios de Método e Historiografía, recomienda combinar el análisis de la normativa constitucional con la práctica político-parlamentaria en las monarquías liberales del Ochocientos.

Estas investigaciones, señala Marcuello, deberían completarse con los estudios comparados con las monarquías europeas más próximas, pues en ellos pueden observarse paralelismos, divergencias o influencias que permiten obtener una visión más aproximada de la distinta evolución y papel político de la Corona en el Estado Liberal decimonónico. Esta línea de análisis constituye, quizá, la vía menos explorada hasta la fecha, puesto que los estudios comparativos de la monarquía española con otras de nuestro entorno -como la portuguesa, italiana, belga, británica, sueca, etc.- son relativamente escasos.

Por todo ello, se pretende presentar al lector un embrionario análisis de las monarquías española e italiana hasta 1900 con el objetivo de estudiar el grado de parlamentarización de ambos países a comienzos del siglo XX. Para ello, en las siguientes páginas se abordan estas tres líneas de análisis anteriormente pergeñadas. En primer lugar, se introducen algunas nociones básicas sobre los tipos de constituciones y las formas de gobierno monárquico en función de la concepción teórica de la propia monarquía, para seguidamente analizar la prerrogativa regia recogida en el marco jurídico vigente en España e Italia en el último tercio del siglo XIX.

A continuación, se analizan las distintas prácticas político-parlamentarias durante la Restauración española y la Italia del Risorgimento, en concreto, la relación Rey-GobiernoCortes y el ejercicio de la prerrogativa regia -para el caso que nos interesa, principalmente 
El uso de la prerrogativa regia en la monarquía española e italiana del último tercio del siglo XIX: ¿Un gobierno parlamentario?

la de formación de Gobierno, disolución de las Cortes y sanción de las leyes-. Con ello se comprueba qué prácticas acercaron estas monarquías a la forma de gobierno parlamentaria y cuáles otras la desnaturalizaron. Finalmente, se expone una elemental comparación de ambos casos -español e italiano- $y$, a modo de conclusión, se intenta dar respuesta a una hipótesis de partida: ¿pueden considerarse las monarquías española e italiana a finales del siglo XIX dos monarquías de gobierno parlamentario?

\section{| Constituciones y formas de gobierno monárquico|}

Varela Suanzes-Carpegna distinguió en su día cuatro etapas en la historia constitucional europea, que se inició en Inglaterra con la revolución "Gloriosa" de 1688 (Varela, 2015). Un segundo periodo se desarrolló con el constitucionalismo revolucionario en Estados Unidos, Francia y el mundo hispánico (1776-1814), al que le seguiría una tercera etapa decimonónica que consolidó y expandió las monarquías constitucionales hasta su quiebra en la Primera Guerra Mundial. El cuarto período, posterior a 1917, estuvo caracterizado por la crisis del estado liberal construido en la centuria anterior y por la caída de la mayor parte de las casas reinantes europeas, entre ellas la española y la italiana. En la tercera etapa señalada por el historiador, casi todas las monarquías europeas abrazaron, con mayor o menor agrado, un modelo constitucional que buscó limitar el poder que los soberanos habían ejercido en épocas anteriores para definir, de este modo, las funciones y el reparto del poder entre la Corona, el gobierno constitucional y el Parlamento (Lario, 1999). No obstante, si bien las monarquías constitucionales fueron el modelo a seguir en la mayor parte de la Europa del Ochocientos, exceptuando el Imperio ruso, aferrado a un sistema político de corte autocrático, las diferentes formas que se presentaron para adecuar la monarquía a las nuevas realidades nacionales mostraron notables diferencias entre unos países y otros.

La primera distinción guardó relación a la concepción temporal de la monarquía respecto a la constitución, es decir, a la compleja disyuntiva sobre si se entendía la monarquía como anterior o posterior a esta $y$, más específicamente, a si el poder monárquico era considerado un poder constituyente o un poder constituido (Marcuello, 2020). En ese sentido, si se concebía la institución monárquica como consecuencia de una Asamblea constituyente que, representando la voluntad nacional, sancionaba una Constitución que la legitimaba, esta era posterior al propio texto constitucional y, por tanto, el poder monárquico era un poder constituido por voluntad de la Nación. Fue el caso de Inglaterra y Holanda, tras aceptar Guillermo de Orange la Bill of Rights de 1689 y Leopoldo I la Constitución belga de 1831, así como la constitución francesa de 1791 y las españolas de 1812, 1837 y 1869, en las que es el propio texto constitucional quien legitima la existencia de la propia monarquía. En ese sentido, la monarquía dejaba de ser concebida como una forma de Estado para convertirse en una forma de gobierno. Constituido ahora en Nación, el Estado la adoptaba en uso de su soberanía (Pascual, 2020). Por el contrario, si se entendía la monarquía como anterior a la propia constitución, nos encontramos con Cartas otorgadas, consecuencia de la voluntad magnánima del monarca, como el caso francés de 1814, el español de 1834 o el italiano de 1848 y con constituciones doctrinarias, que descansaban en un pacto entre el Rey y las Cortes, como las constituciones españolas de 1845 y 1876 (Calero, 1987). Pero en 
ambos casos -otorgadas y doctrinarias-, las Cortes y los textos constitucionales nacían de la convocatoria o voluntad del Rey. Eran, por tanto, posteriores a este, y el poder monárquico se presentaba partícipe -en el caso de las cartas otorgadas- o co-partícipe -en el caso de las doctrinarias o pactadas- en el poder constituyente (Marcuello, 2020).

La segunda diferencia entroncó con el pensamiento político y el concepto de poder surgido tras la revolución inglesa, el gobierno constitucional de Locke y la separación de poderes teorizada por Montesquieu en el siglo XVIII. De estas premisas partieron los teóricos alemanes para concebir lo que debía de ser una verdadera "Monarquía Constitucional”, asignándole al monarca uno de los poderes, el ejecutivo (Lario, 2003). Los ministros guardarían muchas similitudes a los secretarios de Despacho del Antiguo Régimen, siendo únicamente responsables ante el Rey y no teniendo que rendir cuentas ante las Cortes (Heun, 2000). Fue, por tanto, la aplicación de la estricta separación de poderes en su estilo más "puro", si bien en la práctica solamente la monarquía alemana y la República de los Estados Unidos mantuvieron este sistema de gobierno constitucional (Oliver León, 2002). En contraposición, el modelo de gobierno mayoritario en las monarquías europeas del siglo XIX fue el denominado "parlamentario", a imagen y semejanza del modelo inglés. Este modelo se caracterizó por la existencia de un mecanismo institucional que unía directamente el Gobierno y la Cámara representativa de tal manera que el primero solo podía operar si contaba con el apoyo de la mayoría de los diputados (Colombo, 2003). De este modo, existía un equilibrio entre el Rey y las Cortes, cuyo nexo de unión era el propio Gobierno, que requería de la doble confianza para mantenerse en el poder. Si no se contaba con esta confianza, el Gobierno tendría serias dificultades para seguir en el cargo, puesto que el Parlamento comenzaría a derribar sus proyectos de ley o el monarca podría destituir o revocar a los ministros del ejecutivo. Además, este sistema abría la puerta a que los ministros pudiesen desempeñar al mismo tiempo el cargo de parlamentario, por lo que, atentando contra la separación de poderes de Montesquieu, en las monarquías de gobierno parlamentario el ejecutivo solía compatibilizar su puesto con un asiento en la Cámara legislativa ${ }^{2}$. Esta costumbre, siguiendo el modelo británico, buscaba reforzar el apoyo parlamentario del Gobierno, ya que si este se encontraba representado en las Cámaras le resultaba más fácil convencer y conseguir el apoyo parlamentario necesario para sacar adelante sus proyectos y presupuestos. En ese sentido, esta segunda forma de gobierno fue la adoptada por la mayoría de las monarquías de la tercera etapa del constitucionalismo europeo (Varela, 2015), entre ellas Gran Bretaña, Holanda, Bélgica y los países escandinavos $^{3}$, a los que se les fueron sumando, paulatinamente, España, Portugal e Italia.

\footnotetext{
${ }^{2}$ Así ocurrió con los principales líderes políticos españoles e italianos de la segunda mitad de siglo. Cánovas, Sagasta, Minghetti, Depretis - Crispi, entre otros, fueron diputados de sus respectivos Parlamentos mientras desempeñaban sus cargos en el ejecutivo. A medida que avanzó el proceso de parlamentarización de las monarquías española e italiana, la mayoría de los ministros procedían del Parlamento, hasta tal punto que llegó a convertirse en excepción la existencia de ministros no parlamentarios, incluso llegando a reservárseles, en el caso de Italia, el primer puesto disponible en las Cámaras (Lario, 1999).

${ }^{3}$ Sobre el proceso de parlamentarización en las monarquías nórdicas, véase YRAOLA, Aitor (1996): "Evolución de los parlamentos de los países nórdicos: análisis comparado", Revista de Estudios políticos, 93, 67-82.
} 


\section{| El Estatuto Albertino de 1848 y la Constitución de 1876 |}

Con el objetivo de realizar un correcto análisis del uso de la prerrogativa regia, en las páginas siguientes se procederá a comparar el marco jurídico vigente en España e Italia en las últimas décadas del siglo XIX: la Constitución de 1876 y el Estatuto Albertino de 1848. Ciertamente, la comparación lógica de ambos países tendría que hacerse entre el Estatuto Real de 1834 y el Estatuto Albertino de 1848, pues estos documentos no solamente son contemporáneos, sino que, además, son considerados cartas otorgadas y presentan unas características más propensas al estudio comparado. Sin embargo, teniendo en cuenta que el Estatuto Real no estuvo vigente durante la Restauración -pero el Estatuto Albertino lo estará en Italia hasta bien entrado el siglo $X X$-, resulta más oportuno establecer los paralelismos y diferencias entre la normativa de ambos documentos con el objetivo de analizar el ejercicio de la prerrogativa regia en ambos países mediterráneos a finales del Ochocientos.

\section{La monarquía constitucional pura frente a la monarquía de gobierno parlamentario}

Para el caso italiano, el Estatuto de 1848 -creado para el Reino de Cerdeña y asumido después como Carta Magna por el Reino de Italia-, contemplaba un régimen constitucional puro en su origen, es decir, de estricta separación de poderes (Colombo, 2003). Este hecho contrastó con el aparente carácter parlamentario de la Constitución de 1876. El principio que determinaba el sistema constitucional puro italiano se recogía en el artículo 5, por el cual "al Re solo appartiene il potere esecutivo" y en el artículo 65, por el cual "Il Re nomina e revoca i sui ministri”. Sin embargo, el Estatuto no especificaba cómo hacerlo, ni si el Rey tenía que tener en cuenta la composición del Parlamento, ni siquiera si tenía que hacer consultas previas. Colombo (2003) afirma que se trata de una prerrogativa que, formulada de este modo, semejaba bastante a un monarca de Antiguo Régimen. Paralelamente, en el artículo 54 de la Constitución española de 1876 se le otorgaba al Rey la capacidad de "nombrar y separar libremente a los ministros" 5 . En el caso español se observa un claro avance de la forma de gobierno parlamentario a partir de la Constitución de 1837, que se mantuvo con la Constitución de 1845 y la Constitución de 1869 (Lario, 2005). Por este motivo, el teórico derecho a formar el gabinete que el monarca estimase, bajo la vigencia de la Constitución de 1876, fue en la práctica una formalidad en la que el Rey llamaba a formar Gobierno al jefe del partido que contaba con el apoyo mayoritario de las Cámaras (Lario, 1999). Además, fueron los presidentes del Consejo de Ministros quienes se encargaron de elaborar las listas ministeriales, que el monarca se limitaba a ratificar, al igual que había sucedido con Isabel II y Amadeo de Saboya (Pascual, 2020). En el caso de la monarquía italiana, esta práctica no se observó ni en el Estatuto ni en el origen de la nueva monarquía constitucional, ya que los ministros eran responsables solamente ante el monarca, que desempeñaba un papel activo en su designación (Barbera, 2011). Sin embargo, este sistema evolucionó progresivamente en sentido parlamentario con el paso

\footnotetext{
${ }^{4}$ Esta cita y las siguientes relativas a los artículos del documento jurídico italiano se pueden consultar en el propio texto del Statuto Albertino que se encuentra digitalizado en la web de la Presidencia de la República de Italia. Disponible en web en: https://www.quirinale.it/allegati_statici/costituzione/Statutoalbertino.pdf

${ }^{5}$ Esta cita y las siguientes relativas a los artículos del texto constitucional español se pueden consultar en el propio texto de la Constitución de 1876, que se encuentra digitalizada en el Congreso de los Diputados de España. Disponible en web en: http://www.congreso.es/docu/constituciones/I876/I876_cd.pdf
}

SHJ, 2022, 2(I), pp. I-24. ISSN: 2792-3967 
del tiempo, y la monarquía constitucional pura surgida en marzo de 1848 se adaptó a la nueva cultura política, convirtiéndose de este modo en parlamentaria, e instaurándose un mecanismo de interdependencia entre el Gobierno y la Cámara, así como la doble confianza característica del gobierno parlamentario (Colombo, 2003). Con todo, resultaría muy complicado establecer una fecha o momento en el que se pueda considerar el Reino de Italia un régimen parlamentario. Lo que es evidente es que en el reinado de Carlo Alberto y en los años 50 del reinado de Víctor Manuel II esto no se produjo, sino que fue un proceso más tardío, evolutivo y paulatino. La monarquía italiana se fue modernizando y este proceso solo se rompió con la llegada del fascismo, que vació de poder efectivo el Estatuto y el Parlamento italiano (Rebuffa, 2003).

\section{El poder moderador y la irresponsabilidad regia}

En una monarquía constitucional como la española y la italiana, al Rey se le atribuyó el denominado poder moderador, doctrina introducida por Benjamin Constant y basada en la función de armonización de los diferentes poderes a través de la figura neutral y superior del monarca (Bastid, 1966). La idea del monarca como cuarto poder -como árbitro entre los poderes legislativo, ejecutivo y judicial- también enlazaba con la teoría de Bagehot (1867), quien diferenciaba las atribuciones del Rey, como poder dignificado, de las de los ministros del gobierno, a los que les correspondía el poder eficiente. Lario (1997) considera que, si bien el Rey seguía formalmente al frente del Poder Ejecutivo, se fue consolidando paulatinamente una:

Práctica política progresivamente alejada del marco teórico (...), un alejamiento progresivo del monarca del ejercicio del poder, a no ser en las situaciones en que los conflictos entre los poderes le obligaran a actuar en un sentido moderador de los mismos y con el fin de hacer avanzar la vida política (p. 287).

Esta idea se escenificó en la irresponsabilidad del monarca, recogida tanto en el Estatuto Albertino como en la Constitución de 1876. El artículo 4 del Estatuto establecía que "la persona del Re è sacra e inviolabile", mientras que el artículo 48 de la Constitución de 1876 afirmaba que "la persona del Rey es sagrada e inviolable". La responsabilidad política recaía, por tanto, en los ministros que el Rey designaba. Colombo (2003) denomina a este mecanismo "cobertura ministerial", es decir, el Rey es irresponsable y cada acto suyo puede serle imputado a un ministro. El ministro, por su parte, no podía presentar un proyecto de ley como voluntad personal del Rey. Pero, indirectamente, la ley contaba con el respaldo del monarca. Como afirmó en una ocasión Francesco Crispi: "noi, proponendo le leggi, non siamo che gli interpreti del pensiero reale. $\grave{E}$ strano quindi il credere che le leggi possano essere nostre mentre non sono che d'iniziativa sovrana" (Colombo, 2003, p. 224). En España el sistema funcionaba de manera similar, el artículo 49 establecía la responsabilidad de los ministros, y añadía que ningún mandato del Rey podía llevarse a cabo si no estaba refrendado por uno de sus ministros. Para Lario (2000), la idea de la irresponsabilidad regia derivaba del pensamiento inglés de que el Rey no podía equivocarse $y$, en caso de error, serían los ministros quienes asumirían tal responsabilidad. 
El uso de la prerrogativa regia en la monarquía española e italiana del último tercio del siglo XIX: ¿Un gobierno parlamentario?

A pesar de esto, este principio fue cuestionado a lo largo de toda la historia política y constitucional de ambos países. Segismundo Moret llegaría a decir que "desde el momento en el cual se pide al Poder Real que dirima por sí la contienda de los partidos, lo que se hace es echarle encima la responsabilidad de las crisis. Porque esa es la consecuencia de esa teoría" (Lario, 2000, p. 98). Calero Amor (1987), por su parte, diferenció dentro de la irresponsabilidad regia los juicios de constitucionalidad de los juicios políticos, pues "la actuación del monarca puede ser, en términos jurídicos, perfectamente constitucional, y a la vez, en sus consecuencias políticas, perfectamente desacertada" (p. 276). En esa línea de pensamiento se muestra Isabel Pascual (2020) cuando reconoce que "toda monarquía no parlamentaria acaba siendo en realidad responsable, ya que, aun declarando al rey teóricamente inviolable y neutro, le condena volis nolis a no poder ser pasivo". En efecto, la responsabilidad regia se dejó sentir en la opinión pública a lo largo del tiempo, sobre todo en las crisis políticas y sociales más acuciantes, haciendo a la monarquía responsable en última instancia de los problemas políticos, económicos y sociales de la Nación y provocando, en última instancia, la caída de la institución en 1931 en España y en 1946 en Italia.

\section{Principios y preceptos constitucionales}

El Estatuto Albertino y la Constitución de 1876 fueron concebidos para otorgar estabilidad a dos regímenes que partían, o bien de la nada constitucional, en el caso italiano, o de un veleidoso siglo XIX, como en el caso español, en el que se fueron sucediendo una serie de constituciones fallidas. Por ello, para lograr este objetivo de continuidad constitucional, ambos textos son marcadamente ambiguos, con silencios calculados, que remitían a la legalidad vigente diversas leyes polémicas, como la libertad de imprenta o el tipo de sufragio. Rebuffa (2003) dice sobre el Estatuto que: "Era un documento i cui contenuti reali non erano ancora fissati. Questa sarà la sua forza nell'età liberale, ma anche la ragione del suo crollo nella grande crisi politica succeduta alla guerra mondiale" (p. 80). Francisco Silvela, por su parte, llegó a afirmar que "bajo esta Constitución pueden realizarse todas las políticas posibles dentro del sistema monárquico-constitucional" (Villarroya, 1997, p. 106). Ambos documentos eran, por tanto, elásticos, pudiendo recibir interpretaciones distintas para permitir gobernar a fuerzas dinásticas diversas ${ }^{6}$ así como relativamente breves, disponiendo de 84 artículos el Estatuto Albertino y 89 artículos la Constitución de 1876. De este modo, podemos incluir tanto al Estatuto Albertino como a la Constitución de 1876 dentro del grupo de constituciones flexibles, es decir, de fácil reforma o modificación, mediante un acuerdo entre las Cortes con el Rey a través de un procedimiento sencillo, elaborando una ley ordinaria. Así lo defendió Cavour en un artículo publicado el 10 de marzo de 1848: "Ma ciò non vuol dire che le condizioni del patto non siano suscettibili di progressivi miglioramenti operati di comune accordo tra le parti contraenti"7.

Por lo que respecta a los derechos y libertades, en ambos casos estos fueron bastante restringidos y los dos textos los reconocieron muy someramente. Los pocos derechos reconocidos en el Estatuto fueron los principios fundamentales de la libertad surgidos en

\footnotetext{
${ }^{6}$ Catherine Brice (2013) considera que el Estatuto se caracterizaba por una "geometria variabile" que permitió su adaptación a cualquier contexto político y su vigencia durante los casi cien años de la monarquía italiana.

${ }^{7}$ II Risorgimento, 10/03/1848.
} 
la Revolución francesa: la libertad individual, solo "guarantita" en el artículo 26, el derecho de propiedad, en el artículo 29 y la libertad de imprenta, en el artículo 28. Lo mismo sucedió en la Constitución de 1876, que registró los principales derechos recogidos en la Constitución de 1869. El artículo 13 reconocía la libertad de opinión, de imprenta, de reunión y de asociación, pero el artículo 14 remitía a las leyes ordinarias la regulación de los mismos, por tanto, en la práctica los recortaba o censuraba. Por otro lado, en dos países eminentemente católicos, la libertad religiosa solo fue reconocida de forma téorica. Si bien el artículo 11 de la Constitución de 1876 reconocía la tolerancia religiosa, también establecía que "la religión católica, apostólica, romana, es la religión del Estado" y no se permitirían “otras manifestaciones y ceremonias públicas que las del Estado". El confesionalismo también es característico del caso italiano, otorgándole, incluso, más importancia que en el español, puesto que se elevó al artículo 1 el precepto por el cual "La religione Cattolica, Apostolica e Romana è la sola Religione dello Stato. Gli altri culti ora esistenti sono tollerati conformemente alle leggi”.

Otra característica común a ambos textos constitucionales fue su marcado bicameralismo. La Cámara Baja, en España denominada Congreso de los Diputados y en Italia Camera dei Deputati, estaba compuesta por miembros elegidos por el sufragio que establecía la ley electoral vigente en cada país. Al no estar recogida en ninguno de los dos documentos, en la práctica se aseguró un sufragio censitario. El contraste principal de ambos textos se produjo en la Cámara Alta o Senado, puesto que en el caso italiano estuvo compuesto, según el artículo 33, "da membri nominati a vita dal Re", es decir, íntegramente por designación regia y condición vitalicia -semejante al Senado de la Constitución española de 1845-, mientras que, en el caso español, se optó por un Senado de composición mixta concebido como punto intermedio entre el Senado de designación real de 1845 y el electivo de 1869-. Como recogió el artículo 20: "El Senado se compone: 1. ${ }^{\circ}$ De Senadores por derecho propio. 2..$^{\circ}$ De Senadores vitalicios nombrados por la Corona. 3. ${ }^{\circ} \mathrm{De}$ Senadores elegidos por las Corporaciones del Estado y mayores contribuyentes en la forma que determine la ley".

Con relación a la administración de la justicia, es importante tener en cuenta que tanto el Estatuto Albertino como la Constitución de 1876 no la designaron como el tercer poder, sino como un "Ordine giudiziario" el primero y "De la administración de la justicia" el segundo. Para el liberalismo conservador-doctrinario, el poder judicial fue considerado un poder secundario o delegado, que se administraba en nombre del Rey. En España, solo las constituciones redactadas bajo el principio de soberanía nacional recogieron la denominación de "poder judicial"8. Si bien el artículo 68 del Estatuto afirma que "La giustizia emana dal Re ed è amministrata in suo nome dai Giudici ch'egli istituisce”, en la práctica, el Rey tuvo poco que hacer en este ámbito, ya que no podía juzgar en primera persona, prohibido por el artículo 68, ni influenciar a los jueces ni magistrados, que eran inamovibles, preceptos recogidos en los artículos 69 y 70 ; y situación muy similar al texto español, que

\footnotetext{
${ }^{8}$ Recogen la denominación de "poder judicial" la Constitución de 1837, la Constitución non nata de 1856, la Constitución de 1869 y el proyecto republicano federal de 1873 . No así la constitución de 18I2, que habla de los "tribunales de administración de la justicia" (Título V.
} 
El uso de la prerrogativa regia en la monarquía española e italiana del último tercio del siglo XIX: ¿Un gobierno parlamentario?

recogía en el artículo 74 que "La justicia se administra en nombre del Rey".

En otro orden de cosas, tanto el Estatuto Albertino como la Constitución de 1876 no reconocían tampoco la figura del Presidente del Consejo de Ministros. Aunque, en la práctica, este cargo político existió en ambas naciones, sus funciones se fueron precisando a lo largo del tiempo, como director de la política nacional, canal de comunicación entre el Rey y los ministros y cabeza visible del Gobierno. En Italia, en numerosas ocasiones el Presidente del Consiglio mermó la autoridad del Rey, en una lucha por el poder debido a la indefinición constitucional sobre este papel, que no llegó a solventarse hasta el decreto regio de 1901 (Rebuffa, 2003). En él se delimitaron las funciones y obligaciones de este cargo tan voluble en la historia política de la monarquía italiana. En España, por el contrario, las relaciones entre el Presidente del Consejo de Ministros y el Rey o la regente fueron más estables, de tal modo que Cánovas asumió ocho años la Presidencia en el reinado de Alfonso XIl y Sagasta diez de los diecisiete años de la Regencia -a diferencia de la experiencia del Sexenio-. También ambos documentos otorgaron al monarca el mando supremo de las fuerzas armadas. En el caso italiano, este precepto se estableció en el artículo 5 del Estatuto, que decía lo siguiente:

Al Re solo appartiene il potere esecutivo. Egli è il Capo Supremo dello Stato; comanda tutte le forze di terra e di mare; dichiara la guerra; fa i trattati di pace, d'alleanza, di commercio ed altri, dandone notizia alle Camere tosto che l'interesse e la sicurezza dello Stato li permettano, ed unendovi le comunicazioni opportune.

En el caso de la Constitución de 1876, se recogía en el artículo 52 que el Rey "Tiene el mando supremo del Ejército y Armada, y dispone de las fuerzas de mar y tierra". Carlos Dardé (2013) señala que, para Cánovas, se le atribuyó al monarca más autoridad sobre el Ejército que las constituciones españolas anteriores, y según el político malagueño, esto respondía a una "obra meditada de la comisión de Constitución" (p. 321), que buscó consolidar la imagen de un Rey-soldado que se había intentado forjar durante el reinado de Amadeo de Saboya. Le correspondía también al Rey de ambos países declarar las posibles guerras $y$, en su caso, firmar los tratados de paz, así como la dirección de las relaciones diplomáticas y comerciales con las demás potencias, la acuñación de moneda y la concesión de títulos y honores.

En otro orden de cosas, como ya se ha mencionado anteriormente, no se debe olvidar que los dos textos descansaban sobre la idea de una soberanía compartida entre el Rey y las Cortes -para el caso italiano en forma de carta otorgada, mientras que para el español como constitución liberal-doctrinaria-, que otorgó al monarca un fuerte poder político sobre el Parlamento. Entre otras cuestiones, le correspondía a los reyes convocar, suspender, disolver o prorrogar las Cortes, recogido en el artículo 9 del Estatuto Albertino y en el artículo 32 de la Constitución española de 1876, así como la iniciativa legislativa compartida por el Rey y las Cortes, recogido en el artículo 10 del Estatuto y en el 41 de la Constitución de 1876. Las prerrogativas regias de los monarcas españoles e italianos se completaban con el denominado poder residual, es decir, todo aquello que no fuese expresamente atribuido a ningún otro órgano o institución y que, a falta de titular para 
ejercerlo, le correspondía al Rey desempeñar su función.

\section{|El ejercicio de la prerrogativa regia durante la Restauración y el Risorgimento|}

En las páginas que siguen, el lector se hallará frente a una contribución que pretende analizar la práctica de la prerrogativa regia entre los monarcas españoles e italianos de las últimas décadas del siglo XIX -Alfonso XIl y la regente María Cristina de Habsburgo, en España, y Víctor Manuel II y Humberto I en Italia, respectivamente-. Aquí se ha puesto el foco sobre las prerrogativas regias más significativas a la hora de estudiar el ejercicio y desempeño del gobierno monárquico en un sentido parlamentario, estas son, principalmente, las que atañen a la relación Rey-Gobierno-Cortes y al mecanismo de la "doble confianza".

\section{El reinado de Víctor Manuel II (1849-1878)}

La abdicación del rey de Cerdeña Carlo Alberto, en marzo de 1849, trajo consigo la subida al trono de su hijo Víctor Manuel II, el primer monarca que juró la recién aprobada carta otorgada de la monarquía saboyana. El Estatuto Albertino supuso, en definitiva, que el reinado del nuevo monarca se iniciase bajo un paraguas que suponía la modernización jurídica del Reino de Cerdeña y permitió que, tras las anexiones territoriales de los años 50 y a partir de la unificación italiana en 1861, se abriese el camino para la construcción de una política nacional-liberal en el Reino de Italia (Rebuffa, 2003). Tras la muerte del conde de Cavour, en junio de 1861, Bettino Ricasoli se convirtió en el segundo Presidente del Consiglio dei Ministri del nuevo país. Pero el gobierno Ricasoli tuvo que afrontar diversos problemas que contribuyeron a su caída. Fue entonces cuando se puso en evidencia, por primera vez, el atisbo de un gobierno parlamentario en el naciente estado italiano (Ghisalberti, 2000). El 16 de febrero de 1862, el político Urbano Rattazzi envió al Palacio Real una carta en la que exponía cómo tenía que caer el gobierno Ricasoli. Existían, jurídicamente, dos mecanismos legales: el primero de ellos consistía en que el rey Víctor Manuel II lo destituyese por iniciativa propia, tal como estipulaba el artículo 5 del Estatuto. Pero el político piamontés rechazó esta opción, puesto que el monarca sería visto como un tirano, y optó por el "voto di sfiducia" del Parlamento para justificar tal destitución (Colombo, 2003). Sin embargo, este primer indicio de parlamentarización de la monarquía italiana pronto se esfumaría a lo largo de los años 60, dentro del contexto internacional que amenazaba con una guerra con el imperio Habsburgo para resolver la cuestión véneta. Víctor Manuel II, preocupado por este asunto, encargó formar gobierno a militares en los momentos de mayores crisis políticas, para "trovare nell'esercito gli uomini fedeli in grado di risolvere energicamente i problemi dello Stato" (Gentile, 2011, p. 248). Así sucedió con la designación regia de militares como Alfonso Lamarmora, en 1864, o Luigi Federico Menabrea, en 1867. Este último ostentaba, así mismo, el cargo de Primo aiutante di campo en la corte del rey italiano, y el militar formó gobierno con otras figuras cortesanas, entre ellas, el gobernador del Palazzo Reale di Pitti, Luigi Guglielmo Cambray-Digny, y el general Ettore Bertolé Viale, uno de los ocho aiutanti di campo del Rey (Antonelli, 1997). Este 
El uso de la prerrogativa regia en la monarquía española e italiana del último tercio del siglo XIX: ¿Un gobierno parlamentario?

gobierno cortesano, unido a los encabezados por Urbano Rattazzi, en 1862 y 1867, constituyeron verdaderamente unos "governi del re", y se contrapusieron radicalmente a los gobiernos de Alfonso XII, quien evitó en todo momento la influencia de la corte en los asuntos políticos, pues evocaba la época del reinado de su madre, de la que siempre se intentó alejar. El tipo de gobierno italiano de los años 60 ha sido interpretado por varios autores - entre ellos Umberto Levra- como un acercamiento a la forma constitucional pura del Estatuto, alejándose del reconocimiento del poder del Parlamento:

Quello di rappresentare la più pesante ingerenza dinastica mai registrata nella vita política, quasi a riaffermare un'interpretazione puramente costituzionale dello Statuto, in pieno contrasto con quelle prerogative che la prassi seguita sin dai tempi di Cavour aveva riconosciuto al Parlamento (Gentile, 2011, p. 252)

Los tres gobiernos sucesivos de Menabrea, entre 1867 y 1869 , no contaron del mismo modo con el apoyo de Parlamento, y cuando el militar le comunicó al monarca su deseo de dimitir, el Rey rechazó esta idea e incluso abogó por un cuarto mandato (Colombo, 2003). Tal era la voluntad de Víctor Manuel II de que Menabrea continuase en el poder que firmó un decreto de disolución del Parlamento. El fin de esta etapa se debió también a un cambio en el contexto internacional, puesto que 1870 se saldó con la derrota de la Francia de Napoleón III por parte de Prusia (Espadas Burgos, 1990). Un año antes, Giovanni Lanza había sustituido a Menabrea como Presidente del Consiglio, y su acción política se centró en terminar con el gobierno cortesano de la etapa precedente, así como en virar la política exterior italiana hacia Viena y Berlín. En 1873 le sucedió en este cargo Marco Minghetti, uno de los hombres más fuertes de la Destra Storica (Mack Smith, 2002). Carlo Ghisalberti (2000) considera que durante estos años Víctor Manuel II no tuvo en cuenta la mayoría parlamentaria para formar gobierno, pero con la llegada de la Sinistra al poder, según el autor, el régimen estatutario evolucionó poco a poco hacia un parlamentarismo más moderno, tesis que también comparte Paolo Colombo (2003) El hecho que constata este avance del proceso de parlamentarización en la monarquía italiana se produjo en marzo de 1876, cuando el gobierno Minghetti sufrió una derrota en el Parlamento, debido a un cierto número de diputados conservadores disidentes, que se unieron a la Sinistra para derribar al ejecutivo. Víctor Manuel II, entendiendo la necesidad que el Gobierno tenía que contar con la confianza parlamentaria, encargó formar un nuevo gabinete a Agostino Depretis, líder de la “opposizione costituzionale”. Según Ghisalberti (2000), Depretis se mantuvo en el poder por el apoyo de la Cámara, que legitimaba su autoridad política y, al mismo tiempo, sufragaba sus acciones, afianzando de este modo el gobierno parlamentario. Este hecho, además de consolidar un gobierno parlamentario en Italia, constituyó la primera tentativa de acercarse a un sistema de alternancia de partidos de gobierno (Mack Smith, 2002), pero, a diferencia de España, que introdujo esta costumbre a partir de 1885, en el caso italiano los políticos no buscaron un sistema parlamentario de alternancia política (Barral, 2012). El éxito de la Sinistra, al igual que en España, fue debido a la aceptación por parte de la izquierda italiana de la monarquía, proceso que se fue consolidando en los años 60 , cuando los principales líderes de las formaciones mazziniana y garibaldina se fueron pasando a las filas monárquicas (Ghisalberti, 2000). En el momento en que se difuminó la amenaza de una izquierda republicana, su llegada al poder resultó inevitable. 
No obstante, a pesar de la evolución en sentido parlamentario del uso de la prerrogativa regia por parte de Víctor Manuel II, el monarca mantuvo a lo largo de todo su reinado una política intervencionista y marcadamente personal. Aunque fue un rey que respetó el marco jurídico del Estatuto, la prerrogativa regia se dejó sentir a lo largo de sus casi treinta años de reinado, utilizando su poder de disolución para evitar debates parlamentarios peligrosos o para eliminar facciones políticas adversas (Rebuffa, 2003). Además, su papel activo en política se reflejaba en la propia definición que Víctor Manuel Il daba de sí mismo, como "Capo del Governo", en contraposición con el primer ministro que recibía el nombre de "Presidente del Consiglio". Con todo, el Rey defendía usar a los políticos como "marionetas", aunque en la práctica esto no fue tan evidente (Tusell y Queipo de Llano, 2012). Otra muestra de la proverbial intervención del monarca en los asuntos políticos fue su tendencia a presidir personalmente las reuniones del Consiglio dei Ministri, entre dos y tres veces por semana, en las que el Rey firmaba las leyes que le presentaba el gabinete. Solamente al final de su reinado se puede observar un alejamiento del monarca del poder ejecutivo más directo, a finales de los años 70, que podemos encuadrar en ese proceso que Lario (1997) define como el alejamiento del monarca del ejercicio del poder en las monarquías constitucionales de la segunda mitad del Ochocientos. En los últimos años del reinado de Víctor Manuel II se produjo, por tanto, un acercamiento al verdadero ideal de monarca constitucional alejado de la acción política (Mack Smith, 2002), como poder moderador, y a un cada vez más frecuente gobierno parlamentario, que necesitaba de la doble confianza, de las Cámaras y del Rey, para legitimarse en el poder. La muerte de Víctor Manuel II, en enero de 1878, hizo que este proceso evolutivo tuviese que continuar desarrollándose bajo el reinado de su hijo, Humberto I, aunque, como se verá, con traumáticas interrupciones.

\section{El reinado de Alfonso XII (1874-1885)}

Con el pronunciamiento de Martínez Campos en Sagunto, en diciembre de 1874, Alfonso XII fue proclamado Rey de España y volvía al trono, de este modo, una dinastía que lo había perdido durante seis años. El joven rey mostró, a diferencia de su homólogo italiano, sinceras intenciones de convertirse en un verdadero monarca constitucional. Estas convicciones quedaron patentes desde el inicio de su reinado, en febrero de 1875, cuando el propio Alfonso XII compró una serie de libros que versaban sobre la función de un rey en una monarquía constitucional (Lario, 2003). Tales inquietudes asombraron a la clase política y diplomática de la época, llegando a decir de él el embajador inglés, al inicio de su reinado, que sus ideas liberales "lo avecinaban a los partidos revolucionarios" (p. 21). Sin embargo, su incuestionable carácter liberaly constitucional no evitó que el monarca tratase de inmiscuirse en las tareas de gobierno, tal y como reflejó Henry A. Layard el 25 de octubre de 1875 (Dardé, 2013). El representante británico reconoció que el rey español tenía claras intenciones de intervenir en la política nacional de un modo más directo y personal. Y en efecto, como señala Carlos Dardé (2003), Alfonso XIl ejerció la prerrogativa regia en ocho ocasiones, y cuatro con disolución de las Cortes y convocatoria de elecciones. En la mentalidad de Alfonso XII, el gobierno constitucional no significaba abandonar los asuntos de gobierno, sino todo lo contrario, es decir, conocer e informarse de todo el funcionamiento y actividad de los distintos órganos constitucionales (Lario, 
El uso de la prerrogativa regia en la monarquía española e italiana del último tercio del siglo XIX: ¿Un gobierno parlamentario?

2003). El problema residía en que el monarca debía tener en cuenta la composición de las Cortes para elegir gobierno, dentro del papel de poder moderador y la idea de gobierno parlamentario que introducía la Constitución de 1876. Sin embargo, era evidente que las Cámaras no representaban la voluntad general de la Nación debido al opaco proceso electoral y al propio sistema político de la Restauración. De este modo, a falta de guía parlamentaria, el Rey era, en palabras de Lario (2000), un "piloto sin brújula” y Alfonso XII asumió mayores responsabilidades políticas que en una verdadera monarquía de gobierno parlamentario. Esto derivó en que, con Alfonso XII, la mayoría de las crisis fueron, o bien "constitucionales", es decir, aquellas que, bajo el pretexto constitucional de libre elección de ministros, el Rey cambiaba a su ejecutivo, o "políticas", por problemas internos del Gobierno (Lario, 2003).

Las crisis parlamentarias, aquellas que se producían por una derrota del gabinete en las Cortes y que, por tanto, bajo un sistema de gobierno parlamentario harían que el Gobierno cayese al perder la confianza de las Cámaras, fueron, según Lario, prácticamente inexistentes en el reinado de Alfonso XII, y la mayoría se trataban de derrotas "morales", por una pérdida del apoyo parlamentario del Gobierno. Por estos motivos, la balanza de la doble confianza del ejecutivo, fundamental en una monarquía de gobierno parlamentario, se inclinó en el reinado de Alfonso XII claramente hacia el lado del Rey, existiendo, como pone de manifiesto Lario (2000), un verdadero "peligro en que se estaba poniendo a la Monarquía por querer vivir solo de ella, puesto que los partidos para acceder al poder intentaron ganarse a la monarquía sin otros organismos políticos" (pp. 164-165). Esta dinámica, que suponía una seria amenaza para todo el sistema monárquico de la Restauración, intentó ser solucionada con el pacto entre partidos en vísperas de la muerte del Rey en 1885. A pesar de esto, el monarca, consciente del papel que le atribuía la Constitución de 1876, intentó que la independencia de criterio y el sentido liberal fuesen los principios fundamentales de su acción política. Para ello, ordenó a sus ministros que le comunicasen los asuntos más importantes con la suficiente antelación posible, para ser conocedor de antemano de los mismos y contar con la información detallada antes de la celebración del Consejo de Ministros (Dardé. 2013). Asimismo, al igual que Víctor Manuel II en Italia, Alfonso XII tuvo tendencia a presidir personalmente el Consejo de Ministros, una vez a la semana, normalmente los jueves por la tarde. No obstante, su intención de influir en el gobierno de manera directa pronto se vio truncada por su hombre de confianza, Cánovas, quien entendía que el monarca tenía que estar lo más alejado posible del gobierno personal. Al poco tiempo de reinar, Alfonso XII fue consciente de las limitaciones de sus capacidades si verdaderamente quería desempeñar el papel de un rey constitucional, por lo que el escaso margen de maniobra del que disponía para el gobierno efectivo provocó en el rey una profunda decepción (Lario, 2003).

Esta frustración pronto hizo mella en su relación con el político malagueño, que empezó a deteriorarse por la actitud personalista de Cánovas ${ }^{9}$. El propio monarca llegaría a decir, al final de su reinado, en una conversación con el embajador alemán Solms lo siguiente: "Cánovas lo sabe todo, lo decide todo e interfiere en todo, incluso en temas militares de

${ }^{9}$ De hecho, uno de los mayores defectos por los que fue criticado Cánovas, según Carlos Dardé, fue la soberbia (Dardé, 20I3). 
los que no sabe nada, y no tiene en consideración los puntos de vista y las preferencias del rey" (Dardé, 2013, p. 334). Este desgaste provocó que, como en Italia, una vez desaparecida la amenaza revolucionaria y republicana, la izquierda se hiciese con el monopolio del poder. A esto se le añadían las propias convicciones del monarca, que nunca tuvo miedo a que los progresistas controlasen la política nacional (Espadas, 1990). Pero, para poderles otorgar tal confianza, Alfonso XII tuvo que esperar a que estos renunciasen al espinoso asunto de la soberanía nacional. De este modo, a lo largo de los años 70 , al igual que había sucedido en Italia en los años 60, la mayoría de los progresistas y algunos demócratas se fueron adhiriendo, paulatinamente, al régimen nacido en 1876. El primer paso fue la creación, en junio de 1880 , del partido fusionista liderado por los constitucionales de Sagasta, a quien Alfonso XIl encargó formar gobierno en febrero de 1881. Esta fue otra ocasión en la que el monarca hizo uso de la prerrogativa regia de forma no parlamentaria, puesto que quien contaba con mayoría parlamentaria en ese momento eran los conservadores, y el Rey no tuvo en cuenta la composición de la Cámara para elegir gobierno. Las buenas relaciones que mantenía el monarca con los liberales, unido al mayor poder de actuación que disfrutaba con ellos (Dardé, 2001), hicieron que Alfonso XII depositase su confianza en Sagasta hasta octubre de 1883. Sin embargo, en enero de 1884, el Rey volvió a llamar al poder a los conservadores, y encargó formar gobierno a Cánovas, constituyendo un gabinete en el que se incluyó a Alejandro Pidal y Mon, el hombre más importante de la Unión Católica.

La razón residía en la confesión que el Rey le hizo al embajador Solms ese mismo año, por la que reconocía que "por supuesto, Sagasta era mucho más agradable para mí, pero con Cánovas me siento más seguro" (p. 103). Para Carlos Dardé (2001), "resulta comprensible la mayor confianza del rey en la lealtad de los conservadores hacia la Monarquía que en la del complejo conglomerado en que terminó consistiendo el partido liberal" (p.103). Alfonso XIl otorgó la confianza a los conservadores hasta su muerte en noviembre de 1885. Después del fallecimiento del monarca, Cánovas decidió apartarse de la política activa y aconsejó a la regente llamar al gobierno al partido liberal de Sagasta, fortalecido tras la unión de la Izquierda Dinástica y los fusionistas.

\section{El reinado de Humberto I (1878-1900)}

La figura de Humberto I presenta sustanciales diferencias con el carácter y formación del monarca español. En primer lugar, porque el rey italiano no fue preparado para reinar (Mack Smith, 2002), y esto fue debido a que la dinastía de los Saboya mostró tradicionalmente poca preocupación en la educación del heredero al trono ${ }^{10}$. No se les formaba en el arte de gobernar, ni mucho menos en las ideas liberales, sino en la obediencia e instrucción militar. Esto se contrapuso al cabal conocimiento que tenía Alfonso XII de las reglas constitucionales, su vocación liberal y su completa formación recibida en los años anteriores a su reinado ${ }^{11}$. Humberto I aceptó y continuó, sin verdadero conocimiento, una

\footnotetext{
${ }^{10}$ Isabel Pascual (200I) recoge las mismas carencias formativas para su hermano, Amadeo, pues este tampoco contaba con grandes estudios ni un bagaje cultural reseñable. Su educación se había centrado en una formación de tipo militar, al igual de que la mayoría de los Saboya. ' Sobre la educación recibida por Alfonso de Borbón en los años previos a la Restauración, recomiendo la obra de Forsting, Richard (2018). Raising heirs to the Throne in Nineteenth-Century Spain. Londres: Palgrave.
} 
El uso de la prerrogativa regia en la monarquía española e italiana del último tercio del siglo XIX: ¿Un gobierno parlamentario?

praxis parlamentaria que se había iniciado en el reinado de su padre, sin cuestionarla y sin presentar ambiciones personalistas en una primera etapa. Este tipo de gobierno se mantuvo, asimismo, al acceder al Trono el segundo rey de Italia, ya que como el Presidente del Consiglio tenía que contar, teóricamente, además de la confianza del Parlamento, de la aceptación del monarca, Depretis presentó su dimisión al nuevo rey. Humberto I, entendiendo que el político italiano todavía disfrutaba del respaldo de la mayoría parlamentaria, rechazó tal dimisión y confirmó la confianza regia en Depretis, "subordinando la propria volontà a quella della Camera elettiva” (Ghisalberti, 2000, p. 178).

Sin embargo, a pesar de que tradicionalmente se ha visto el paso de la corona de Víctor Manuel II a Humberto I como una disminución del papel del monarca en los asuntos políticos, los excesos en el uso de la prerrogativa regia se dejaron sentir a lo largo del reinado del "re buono". Así, en la primavera de 1880, el Rey rechazó la dimisión del tercer gobierno de Benedetto Cairoli, y al pedirle este que hiciese uso de su prerrogativa para disolver las Cámaras y convocar elecciones, Humberto I intervino para mantener en el poder al ejecutivo. Lo mismo sucedió en abril de 1881 y mayo de 1883, cuando las crisis gubernativas o parlamentarias fueron resueltas dirigiéndose a la decisión y voluntad regia. La balanza de la doble confianza, como en el caso de España, también se inclinó a favor del monarca en los momentos de mayores crisis, y los partidos buscaron el amparo del Rey si se encontraban débiles en el Parlamento para mantenerse en el poder (Colombo, 1999). No obstante, la crisis de gobierno más importante durante el reinado de Humberto I se desarrolló al inicio de 1887. El monarca decidió actuar autónomamente, puesto que había tenido numerosos desencuentros con el conde de Robilant, ministro de Exteriores del noveno gobierno Depretis y, por decisión personal, se reunió con Rudinì para formar un nuevo ejecutivo. La voluntad regia se impuso, puesto que, aunque el gobierno Depretis no cayó, Humberto I sí que consiguió hacer cumplir sus deseos y se llevó a cabo una reformulación ministerial. Javier Tusell y Queipo de Llano (2012) consideran que el Rey fue más consciente que su padre de la necesidad de que sus poderes fueran más limitados, sobre todo al inicio de su reinado, y esto se reflejó en que, a diferencia de Víctor Manuel II y de Alfonso XII en España, Humberto I presidió muchos menos Consigli dei Ministri que estos dos monarcas, costumbre que también mantendrá Víctor Manuel III.

No obstante, sería equivocado pensar que a partir de Víctor Manuel II el Rey solo presidió las reuniones del Consiglio al inicio de cada reinado. En realidad, el monarca fue llamado a presidir estas reuniones en circunstancias extraordinarias, como, por ejemplo, tras la derrota de Adua en 1896, que coincidió con un viaje de Humberto I a Nápoles, o en casos de discordia entre los ministros, o entre estos y el Parlamento (Colombo, 2003). Aunque el monarca, con esta práctica, se alejaba de la vida política cotidiana y del trato de los asuntos más específicos en sus reuniones con los ministros, esto no impidió que, a medida que avanzó su reinado, el Rey intentase recobrar mayor protagonismo en la política nacional italiana. Por otro lado, durante el reinado de Humberto I se abrió paso el sistema político conocido como trasformismo ${ }^{12}$. Colombo (2003) y Barbera (2011) defienden que

\footnotetext{
${ }^{12}$ El término trasformismo fue empleado por primera vez en un discurso electoral de Depretis en I876, en el que apelaba a la "trasformazione dei partiti" y a la consolidación de un bloque parlamentario sin diferenciación entre derecha e izquierda (Barral, 20I2).
}

SHJ, 2022, 2(I), pp. I-24. ISSN: 2792-3967 
es tanto en el reforzamiento de la autoridad regia como en la crisis del parlamentarismo donde se tiene que entender la "soluzione trasformista" utilizada en los años 80 . Todo lo contrario consideran Marina Tesoro y Maurizio Ridolfi (2011), pues argumentan que la existencia de un gran centro político garantizó, en la práctica, una forma de gobierno parlamentaria. Esto se conseguiría porque los bloques parlamentarios perdieron la identificación tradicional de derecha e izquierda para garantizar la estabilidad, mediante un trasvase de las filas del gobierno a la oposición y viceversa. En Italia, al igual que en España, era el Gobierno el que hacía las elecciones y construía el resultado electoral que garantizaba el Parlamento deseado y no al revés, por lo que el parlamentarismo italiano acabó consistiendo en mayorías orgánicas en torno a un líder político, que había logrado apoyos transversales en la Cámara. Como señala Margarita Barral (2012): "La misma formación del Gobierno era la que creaba esa mayoría, y no al contrario, creándose siempre un parlamento favorable a la política de intereses” (p. 45). Este sistema no impidió que la autoridad del monarca frente al Parlamento se incrementase en los últimos años del reinado, entre 1890 y 1900. De hecho, Catherine Brice (2004) considera que el reinado de Humberto I se puede dividir en dos etapas bien diferenciadas. Una primera, que llega hasta 1890, caracterizada por la "loyauté du soverain, son respect de la Constitution, son amour du peuple” (p. 44) y una segunda a partir de ese año en la que la imagen del Rey cercano a su pueblo se desvaneció, ganando peso la deriva personalista del monarca. Esta inversión de ruta fue, en parte, debida al gobierno de Francesco Crispi que, desde 1887, es considerado por muchos autores como un gobierno casi dictatorial por sus marcados tintes autoritarios (Mack Smith, 2002). Humberto I sentía animadversión hacia el político siciliano, pues veía en él una sombra a su poder regio, por lo que, con la dimisión de Crispi en 1891, el Rey intentó reafirmar su papel como soberano. Así, Colombo señala que el nombramiento de Giovanni Giolitti como nuevo Presidente del Consiglio, en mayo de 1892, fue decidido "per una scelta personale del Re" (Colombo, 1999, p. 362).

A pesar de esto, la marcha de los acontecimientos provocó el retorno de Crispi en diciembre de 1893, ya que convenció al Rey de la necesidad de un gobierno fuerte que aumentase los gastos militares y recuperase el prestigio internacional del Reino de Italia, dentro una política exterior inserta en la carrera colonial. De hecho, la política expansionista fue uno de los pocos asuntos en donde estuvieron de acuerdo Humberto I y Francesco Crispi, pero esta aventura colonial se saldó con la derrota italiana en Adua, en marzo de 1896. Este fracaso marcó el inicio del proceso de descomposición de la monarquía de Humberto I, que terminaría de manera abrupta en 1900. Dos analistas políticos de la época, Arturo Labriola y el periodista Mario Missiroli, afirmaron que a partir de Adua "Ia monarchia italiana si trova molto decaduta nell'opinione del paese" y que "dal'96 la monarchia non è più oggetto di riverenza, ma di discussione" (Tesoro y Ridolfi, 2011, p. 55). Las injerencias de Humberto I en la política italiana y su deriva personalista contaron, a pesar de todo, con el apoyo de buena parte de la clase dirigente del Reino. Así lo recogía el político Sidney Sonnino en un artículo publicado en 1897 y titulado "Torniamo allo Statuto"13, que defendía la vuelta al carácter constitucional "puro" que amparaba el Estatuto 
El uso de la prerrogativa regia en la monarquía española e italiana del último tercio del siglo XIX: ¿Un gobierno parlamentario?

Albertino:

(...) Senza dubbio alcuno, il parlamentarismo, quale si esplica in Italia, è ammalato (...) Non è, del resto, solo in Italia che ciò si verifica. II Governo parlamentare è messo in questione in tutto il continente europeo, dovunque con questa espressione si è inteso il governo del Parlamento (...) Vogliamo la monarchia liberale e rappresentativa dello Statuto, col Monarca principe effettivo ed attivo, non consegnato bendato nelle mani di un «maire du palais» che si chiami il presidente del Consiglio.

De esta forma, Sonnino propugnaba la inversión de la tendencia que desde 1848 había atribuido mayor poder al Parlamento en detrimento de la Corona, para regresar así a la idea de la monarquía constitucional pura de separación de poderes, que garantizaba que el Gobierno dependiese únicamente del Rey y no tanto del Parlamento. Estas ideas sobre el reforzamiento de la autoridad regia, unidas a la elevada conflictividad social de finales del XIX, vinieron acompañadas de una política represiva por parte de Humberto I, que firmó su sentencia de muerte en mayo de 1898. Este año, el Rey encomendó a un general, Fiorenzo Bava Beccaris, sofocar unas manifestaciones en Milán por el hambre que estaba padeciendo la zona. La sublevación terminó con decenas de muertos y heridos por las calles y plazas de la ciudad italiana. Este hecho fue muy criticado por la opinión pública y la prensa de la época, que el Gobierno intentó censurar sin éxito. Si bien, como señala Brice (2004), los defensores de Humberto argumentaron que el Rey había estado "mal conseillé", esta actuación puso en evidencia que la irresponsabilidad regia atribuida al monarca en el Estatuto Albertino -y en la mayoría de las monarquías constitucionales resultaba, en la práctica, una quimera, puesto que parte de la responsabilidad fue atribuida al propio Rey, al haber permitido utilizar las armas en unas circunstancias innecesarias. Asimismo, en un último intento por controlar la caótica situación, Humberto I optó por el retorno a la vieja política de Víctor Manuel II de los años 60, la de designar militares al frente del ejecutivo en busca de la pacificación del país.

De este modo, el monarca nombró al general Pelloux, en junio de 1898, Presidente del Consiglio. Colombo (2003) afirma que el militar puso de manifiesto la elevada autoridad regia que mostró Humberto I a final de siglo, llegando a constituir su segundo gobierno sin realizar ningún tipo de consultas por parte del monarca, provocando la crispación e indignación de las Cámaras legislativas. La deriva personalista del monarca en los años 90 tuvo su trágico desenlace el 29 de julio de 1900, cuando en nombre de los sucesos de Milán ocurridos dos años antes, el anarquista Gaetano Bresci acabó con la vida de Humberto I en Monza. Se ponía fin, de este modo, a un reinado de un monarca incapaz de desprenderse de su tendencia autoritaria en favor de un verdadero gobierno parlamentario. Su sucesor, Víctor Manuel III, consciente de los errores que había cometido su padre, intentó aplicar de forma plena este sistema de gobierno, evitando intervenir en las esferas de decisión política. Pero las buenas intenciones del nuevo monarca pronto se desvanecerían, en un periodo en el que la monarquía constitucional italiana se iría descomponiendo inexorablemente. 


\section{La regencia de María Cristina de Habsburgo (1885-1902)}

María Cristina de Habsburgo-Lorena asumió la regencia de su hijo Alfonso tras la prematura muerte de su esposo Alfonso XII, jurando fidelidad a la Constitución de 1876 como prescribía el artículo 69 de la misma. La muerte de Alfonso XII y la carencia de un heredero adulto varón provocó la única crisis de la monarquía española del último cuarto de siglo (Lario, 2000). Para evitar su colapso, la solución empleada se fraguó en el denominado "Pacto del Pardo", en 1885, por el que se introducía en España el sistema turnista. Barral (2013) establece que el pacto entre conservadores y liberales, bajo el paraguas de la reina regente, consistía en "la alternancia pacífica en el poder con el fin inmediato de eliminar la inestabilidad política que se había vivido durante la mayor parte del siglo XIX y que había desembocado en la militarización de la política y en la politización del ejército" (p. 47). Al igual que en el trasformismo italiano, se buscaba alejar de las esferas del poder a republicanos, socialistas, regionalistas y carlistas, para garantizar, de este modo, el gobierno efectivo de los partidos afines al régimen. Si bien este sistema no atentó contra el gobierno parlamentario, sí que lo deformó, puesto que, en la práctica, no eran las Cortes quienes depositaban su confianza en el Gobierno ${ }^{14}$, como tendría que ocurrir en una monarquía de verdadero gobierno parlamentario, sino que era este quien elegía la composición del Parlamento. Tras una crisis gubernativa, el monarca encargaba liderar el ejecutivo al jefe del partido dinástico de la oposición, para garantizar así la alternancia pacífica en el poder. Como el ejecutivo tenía que contar con la doble confianza de un régimen parlamentario, es decir, la del Rey y la de las Cortes, el nuevo Gobierno convocaba unas elecciones que se saldaban con la victoria del partido en el poder. Como dijo en su día Sánchez Agesta, el gobierno parlamentario fue, en definitiva, "una ficción que dio un juego estable durante un cuarto de siglo" (Villarroya, 1997, p. 115).

Esta doble confianza del Gobierno fue, por tanto, una ilusión, puesto que el ejecutivo fabricaba los resultados electorales que le otorgaban la mayoría en el Parlamento ${ }^{15}$, garantizando, de esta manera, la confianza de la Cámara y el apoyo parlamentario requerido. En ese sentido, la regente María Cristina entendió pronto el funcionamiento de este sistema y se introdujo rápidamente en la sutil participación política. Aconsejada por Cánovas, la reina inició su Regencia con los liberales, en noviembre de 1885, ya que, al igual que su difunto marido, compartía mayor afinidad y simpatía con ellos que con los conservadores. El "gobierno largo" de Sagasta se prolongó hasta julio de 1890, y buscó crear de la Regencia y de María Cristina una imagen de renovación, que culminó con la aprobación del sufragio universal masculino. María Cristina otorgó durante tanto tiempo

\footnotetext{
14 La legitimación del poder político en España e Italia mostraba en esta época un carácter descendente en vez de ascendente, como cabe pensar en las democracias actuales. Los ciudadanos con derecho a voto no elegían a los gobernadores ni diputados a nivel regional, sino que eran estos, en la práctica, quienes construían una campaña electoral y fabricaban unos resultados que mantenían en el poder al cargo político correspondiente.

${ }^{14}$ Esto se lograba a través del complejo entramado burocrático-administrativo y los diferentes niveles de gobierno en los que se organizaron los estados liberales en España e Italia. El Reino de Italia estaba dividido en provincias gobernadas por los prefetti, que solían ser amigos del monarca mientras que, en España, sus homólogos, los gobernadores civiles, también mostraban cierta dependencia de la monarquía, y su vinculación con la capital. El sistema se nutría de igual modo del trabajo que en los municipios ejercían los alcaldes en España y los sindaci en Italia, que construyeron una red clientelar que Barral (20I2) insiste en que sobrepasaba los límites meramente electorales. Este fraude se completaba con los caciques españoles y los galoppini italianos, que a escala local llevaron a cabo un sinfín de actuaciones de intimidación, persuasión, compra de votos a cambio de favores entre la población y, en última instancia, los famosos "pucherazos" que convirtieron las elecciones en ambos países en una corruptela.
} 
El uso de la prerrogativa regia en la monarquía española e italiana del último tercio del siglo XIX: ¿Un gobierno parlamentario?

su confianza a los liberales de Sagasta no por convicciones políticas personales (Moreno y Casado, 2014), ya que no tenía profundas creencias liberales -influenciada también por la tradición absolutista de su país-, sino que este acercamiento respondió más bien a su comodidad y trato con el Partido Liberal. No obstante, la reina regente entendió el significado del turno, y, por ello, en 1890 llamó a Cánovas para que tomase de nuevo las riendas del poder. Como le confesó a Vega Armijo, su decisión de encargar formar gobierno a Cánovas se tomó porque, de lo contrario, "quién sabe lo que habrían dicho, porque suponían que yo abandonaba a los conservadores porque tenía una gran preferencia por los liberales, y esto último es verdad” (Lario, 2000, p. 253). En ese sentido, María Cristina comprendió la necesidad de provocar crisis gubernativas "oportunas" para el cambio de gobierno (Sainz de Medrano, 2007), y así se evidenció en su intervención directa en la crisis de 1890. Esta crisis fue presentada ante la opinión pública como una intriga cortesana, puesto que tenía difícil explicación, y "se creó entonces una atmósfera turbia en torno a ella, de difamaciones, calumnias y desmentidos (...) y que acabó cuando el partido conservador salió del poder" (Lario, 2000, p. 290). Con María Cristina las crisis fueron normalmente extraparlamentarias, mientras las Cortes permanecían cerradas, otra ficción más del régimen parlamentario y del sistema turnista. Se llegó, incluso, a culpar a la regente de cocinar las crisis políticas en los salones de Palacio, tanto la de 1890, por la que los conservadores llegaron al poder, como durante el largo intervalo de tiempo en el que estuvieron cerradas las Cámaras, entre el 15 de julio de 1891 y el 11 de enero de 1892.

Por ello, en 1892, María Cristina abogó por una crisis de origen parlamentario para justificar el cambio de gobierno. $Y$ así se hizo tras la reapertura de las Cortes, que evidenciaron la división interna en las filas conservadoras, por lo que Cánovas, sin el apoyo parlamentario, presentó su dimisión. El 10 de diciembre de 1892 María Cristina encargó formar gobierno a Sagasta, que mantuvo la presidencia del Consejo de Ministros hasta marzo de 1895 cuando, aplicando el turno, se volvió a ceder el poder otra vez a Cánovas, quien asumió la presidencia del Consejo hasta su asesinato el 8 agosto de 1897. Con todo, la regente consiguió mantener en estos años, a pesar de las numerosas críticas, una imagen de independencia frente a las presiones políticas o las ambiciones cortesanas (Moreno y Casado, 2014), encarnando el poder moderador que la Constitución de 1876 otorgaba a la Corona. El conde de Romanones llegó a afirmar de ella que: "en los dieciséis años en que hubo de ejercer sus funciones, no se le pudo achacar la más leve falta contra la letra de la Constitución y el espíritu del régimen parlamentario" (Villarroya, 1999, p. 112). Pero, como distinguió en su día Calero Amor (1987), si bien María Cristina cumplió los preceptos constitucionales y no se le puede acusar de actuaciones inconstitucionales, sí que le fueron imputados a lo largo del tiempo errores políticos, llegando incluso a responsabilizarla de las diferentes crisis ocurridas bajo su regencia. Al igual que con Humberto I, la imagen pública de la reina sufrió un desgaste a finales de siglo. Paralelamente al caso italiano, que se produjo por una cuestión colonial -a partir de la derrota de Adua, en 1896-, en España sucedió con el desastre de 1898.

La crisis del 98 no supuso solamente la pérdida de las últimas colonias españolas en América, sino que se culpabilizó a la regente de la derrota sufrida, poniéndose en cuestión, como en Italia, el principio constitucional de la irresponsabilidad regia en las decisiones SHJ, 2022, 2(I), pp. I-24. ISSN: 2792-3967 
políticas. Esto provocó un cambio de rumbo en María Cristina, que se decantó por el conservadurismo católico de Silvela y Polavieja para intentar revertir la situación de decadencia en la que se hallaba la nación. Así pues, en sus últimos años de regencia fue acusada de excederse en sus funciones arbitrales y constitucionales, así como de inmiscuirse en la vida interna de los partidos (Moreno, 2011). El gobierno de Silvela, desde marzo de 1899, fue incapaz de frenar el enorme descontento social que atravesaba el país después de la derrota sufrida en la guerra hispano-norteamericana de 1898 y del aumento de los grupos contrarios al sistema político de la Restauración, entre ellos, los socialistas, los carlistas, los nuevos nacionalistas periféricos y algunos sectores del Ejército. Los albores del nuevo siglo comenzaban así con una serie de programas regeneracionistas para intentar salvar el régimen monárquico de 1876, cuya última baza era el inicio del reinado del joven Alfonso XIII, proclamado mayor de edad a los 16 años y que juró como Rey de España en mayo de 1902. Bajo una proclama regeneracionista recogida en el diario El Norte de Castilla según la idea de que: "Alfonso XII restauró la Monarquía, sea Alfonso XIII el restaurador de la Nación” (Lario, 2007, p. 269), un anhelo de esperanza ponía fin a la regencia de su madre María Cristina de Habsburgo. Estas grandes expectativas regeneracionistas pronto fueron desapareciendo, como en el caso italiano, a medida que avanzaba el convulso siglo $X X^{16}$.

\section{| Conclusiones |}

La teoría y la normativa constitucional, por un lado, y, por otro, la práctica política y parlamentaria en España e Italia en el último tercio del siglo XIX hacen difícil considerar como monarquías de gobierno parlamentario a estos dos países aquí estudiados. En primer lugar, porque sus Parlamentos carecieron en esta época de una representatividad real, pues eran elegidos por el Gobierno de turno y debían, por tanto, su existencia al "trabajo" desempeñado por el ejecutivo, asumiendo, en muchas ocasiones, una cierta postura de irrelevancia política en las decisiones del monarca. Así, habiendo elegido y teniendo controlado el Parlamento, el Gobierno solo tenía que contar con la confianza del Rey para mantenerse en el poder, ya que era el monarca quien nombraba, en teoría libremente, a los ministros. Estos contaban ya con la confianza parlamentaria, puesto que habían construido fraudulentamente la composición del Parlamento para la consecución de tal fin. Por su parte, al Rey no le quedaba otra opción que utilizar su propio instinto personal para formar Gobierno, ya que conocía el funcionamiento del sistema y el peliagudo origen de la composición del Parlamento nacional. En esa línea, la crisis del parlamentarismo en ambos países se tiene que encuadrar en el origen y desarrollo de los sistemas políticos conocidos como "turnismo" en España y trasformismo en Italia. En la práctica, fueron los causantes del deterioro de la doble confianza que un sistema parlamentario exiǵa para su correcto funcionamiento, eliminando de este modo la confianza de la cámara legislativa e

\footnotetext{
${ }^{16}$ El sistema turnista mostró claros signos de colapso al poco tiempo de la subida al trono de Alfonso III, en I902, con la progresiva pérdida de poder de los partidos dinásticos en las principales ciudades como Madrid y Valencia y regiones enteras como Cataluña o País Vasco. Sin embargo, Barral (2012) considera que, en el resto del territorio nacional, el sistema turnista perdurará, eso sí, de manera imperfecta, hasta la llegada de Primo de Rivera en 1923.
} 
El uso de la prerrogativa regia en la monarquía española e italiana del último tercio del siglo XIX: ¿Un gobierno parlamentario?

inclinándose del lado monárquico para sostener al régimen.

Resulta complejo, por tanto, esclarecer el carácter parlamentario o no de las monarquías española e italiana a la altura de 1900. Evidentemente, no pueden ser consideradas de tipo constitucional "puro" a imagen del modelo germánico, pero tampoco sería acertado definirlas como unas monarquías parlamentarias de modelo británico o semejantes a las monarquías constitucionales del norte de Europa. Ambas monarquías, la española y la italiana, se acercarían más a un régimen mixto, un tipo de monarquía pseudo-parlamentaria a caballo entre las monarquías de gobierno eminentemente parlamentario y las de estricta separación de poderes. Aparentemente, serían monarquías de gobierno parlamentario, pero la cultura política de ambas naciones adaptó el modelo parlamentario a las peculiaridades de los dos países, desvirtuando tal propósito y convirtiendo, en la práctica político-parlamentaria, la forma de gobierno monárquico español e italiano en una especie de híbrido que fue evolucionando en una u otra dirección en función del contexto político de cada momento.

En ese sentido, el problema de base se encontraba dentro del propio marco jurídico de estas monarquías liberales, pues tanto la Constitución de 1876 como el Estatuto Albertino presentaron unos silencios calculados que hacían posible una variada interpretación del texto. Esta indefinición de las competencias de la monarquía provocó que a lo largo de la historia política de ambos países se sucediesen una serie de crisis en las que, por un lado, si el monarca intervenía, se le acusaba de excederse de sus funciones arbitrales, pero si, por el contrario, se presentaba como un poder neutral o moderador, se le pedía que hiciese uso de su prerrogativa regia para poner fin al conflicto en cuestión. Esta falta de precisión y delimitación funcional de la monarquía liberal supuso un verdadero quebradero de cabeza para la actuación política de los reyes decimonónicos, encontrándose en una posición intermedia en la que, dependiendo del contexto, se acercaban a una u a otra forma de gobierno monárquico, siendo esto letal para la propia institución. A la ausencia de unas líneas rojas que marcasen qué podía o no podía hacer el Rey, se le unieron unas prácticas político-parlamentarias que suponían un sinfín de excesos en el uso de la prerrogativa regia que, a largo plazo, acabaron por eclipsar a todas las monarquías constitucionales que no iniciaron un imperioso cambio de rumbo. Este cambio pasaba, irremediablemente, por un proceso de democratización que ni la monarquía española, ni la italiana, ni buena parte de las europeas lograron llevar a cabo con éxito en las primeras décadas del Novecientos. Por todo ello, las monarquías pseudo-parlamentarias de España e Italia, lejos de evolucionar en las primeras décadas del siglo $X X$ en la dirección de un proceso efectivo de parlamentarización y democratización, se fueron alejando cada vez más de este ideal, lo que provocó, a la postre, la caída de las monarquías de Alfonso XIII en España y de Víctor Manuel III en Italia, respectivamente. 


\section{Referencias}

Antonelli, R. (1997). II Ministero della Real Casa nel primo quarantennio dopo I'Unità'. En Filippo Mazzonis (a cura di), La Monarchia nella storia dell'Italia unita: problematiche ed esemplificazioni (pp. 59-79). Bulzoni.

Bagehot, W. (1867). The English Constitution. The Fortnightly Review.

Barbera, A. (2011). Il governo parlamentare dallo Statuto albertino alla Costituzione republicana. Ordinario di diritto costituzionale, 46 pp.

Barral, M. (2012). Political Clientelism in the Latter Stages of Liberalism: Mediterranean Europe. The International Journal of Civic, Political and Community Studies, 10, 39-54.

Bastid, P. (1966). Benjamin Constant et sa doctrine. Armand Colin.

Brice, C. (2004). La monarchie et la construction de l'identite nationale italienne. Institut d'Estudes Politiques de Paris.

Brice, C. (2013). La monarchia e la nazionalizzazione degli italiani (1861-1900). Memoria e Ricerca, 42, 69-86.

Calero, A. M. (1987). La prerrogativa regia en la Restauración: teoría y práctica (18751902). Revista de Estudios Políticos. Nueva época, 55, 273-315.

Colombo, P. (1999). II re d'Italia: prerogative costituzionali e potere politico della Corona (18481922). F. Angeli.

Colombo, P. (2002). I presupposti dello Statuto Albertino, dai moti del 1821 alle riforme del 1847. Storia costituzionale, 3, 147-170.

Colombo, P. (2003). Con lealtà di Re e con affetto di padre. Torino, 4 marzo 1848: la concessione dello Statuto Albertino. II Mulino.

Colombo, P. (2003). Storia costituzionale della monarchia italiana. Laterza.

Dardé, C. (2001). Alfonso XII. Arlanza.

Dardé, C. (2003). La política en el reinado de Alfonso XII. Marcial Pons.

Dardé, C. (2013). Antonio Cánovas y el liberalismo conservador. Gota a Gota.

Espadas, M. (1990). Alfonso XIl y los orígenes de la Restauración. CSIC.

Gentile, P. (2011). L'ombra del Re Vittorio Emanuele II e le politiche di Corte. Carocci.

Ghisalberti, C. (2000). Storia costituzionale d'Italia (1848-1948). Laterza. 
El uso de la prerrogativa regia en la monarquía española e italiana del último tercio del siglo XIX: ¿Un gobierno parlamentario?

Heun, W. (2000). El principio monárquico y el constitucionalismo alemán del siglo XIX. Fundamentos: Cuadernos monográficos de teoría del Estado, derecho público e historia constitucional, 2, 559-586.

Lario, A. (1999). Monarquía constitucional y gobierno parlamentario. Revista de estudios políticos, 106, 277-288.

Lario, A. (2000). El rey, piloto sin brújula. La corona y el sistema político de la Restauración (18751902). UNED-Biblioteca Nueva.

Lario, A. (2003). La monarquía Constitucional: Teoría y práctica política. En F. Portero (eds.). La Corona en la historia de España (pp. 105-145). Biblioteca Nueva.

Lario, A. (2007). Monarquía y república en la España contemporánea. Biblioteca Nueva.

Marcuello, I. (2020). Rey, Cortes y Formas de Gobierno en la Monarquía Liberal española del siglo XIX. Criterios de Método e Historiografia. In Itinere.

Moreno, M. (2011). María Cristina de Habsburgo, la (in)discreta regente. En Emilio La Parra (coord.), La imagen del poder. Reyes y regentes en la España del siglo XIX (pp. 389-431). Síntesis.

Moreno, M. y Casado, M. A. (2014). María Cristina de Borbón y María Cristina de Habsburgo, dos regentes entre los modos aristocráticos y burgueses. Historia y política, 31, 113-138.

Oliver, B. (2002). Monarquía y Estado constitucional. La institución monárquica en el proceso de consolidación del Estado constitucional. TECNOS.

Pascual, I. (2001). La Italia del Risorgimento y la España del Sexenio Democrático: de los precedentes a la crisis del Sexenio (1860-1874). CSIC.

Pascual, I. (2020). Teoría y práctica de la monarquía nacional y democrática. La constitución de 1869 y su forma de gobierno. Bulletin d'Histoire Contemporaine de l'Espagne, 55, 19 pp.

Rebuffa, G. (2003). Lo statuto Albertino. II Mulino.

Sainz de Medrano, R. M. (2007). La reina María Cristina. Madre de Alfonso XIII y regente de España. La Esfera de los Libros.

Tesoro, M. y Ridolfi, Maurizio (2011). Monarchia e Repubblica. Istituzioni, culture e rappresentazioni politiche in Italia (1848-1948). Mondadori.

Tomás Villarroya, J. (1997). Breve historia del constitucionalismo español. Centro de Estudios Políticos y Constitucionales.

Varela, J. (2009). Constitución de 1876, S.A. lustel. Portal de Derecho.

Varela, J. (2015). Las cuatro etapas de la historia constitucional comparada. Biblioteca virtual Miguel de Cervantes, 15 pp. 


\section{Nota biográfica}

Aitor Alaña es graduado en Historia (2019) y graduado en Economía (2019) por la Universidad Rey Juan Carlos, con premio extraordinario de fin de grado en ambas titulaciones. Realizó el Máster en Historia Contemporánea en la Universidad Complutense de Madrid (2020) y el Máster en Formación del Profesorado de Educación Secundaria, Bachillerato, FP e Idiomas en la Universidad Rey Juan Carlos (2021). Actualmente desarrolla su tesis doctoral como Personal Docente e Investigador en Formación (Contrato Formación Profesorado Universitario) en el área de Historia Contemporánea del departamento de Historia Moderna e Historia Contemporánea de la Universidad Complutense. Es miembro de la Sociedad Española de Excelencia Académica (SEDEA) y coordinador del Seminario Permanente de Investigación en Historia Contemporánea de la UCM. Sus líneas de trabajo son la historia política del siglo XIX y la historia biográfica. Es miembro del proyecto de investigación "Cultura del honor, política y esfera pública en la España liberal (1833-1890)", financiado por el Ministerio de Ciencia, Innovación y Universidades. 